\title{
Council Report from Leipzig
}

A record 130 physicists assembled in Leipzig during the week beginning 5 April for the meetings of Council, the Executive Committee and a number of Advisory Committees and Divisional Boards which use such an occasion to maximize the number of participants in their own discussions whilst minimizing the expenses involved. The arrangements made by the DDR Physical Society were exemplary and the evening lecture by $A$. Lösche on "NMR Investigations in Condensed Matter" a model of clarity.

Council began by hearing a report from the Advisory Committees starting off with ACAPPI which announced it is to hold, in late March, 1977 in collaboration with the Condensed Matter Division, a conference on "Luminescence Processes in Phosphors for Cathode Ray Tubes and Lamps".

The Conference Committee has received about 20 new applications for EPS sponsorship since Bucharest, the majority emanating from the Divisions. There was admittedly, a serious unbalance between East and West in the number of conferences seeking sponsorship or announced in Europhysics News, but this was a situation that had been under active study and it was hoped that a progressive improvement would be seen from now on.

Approval was given to the Physics and Society Committee's proposal that there should be an informational award established, the first of which would probably be presented at the next General Conference. Details have still to be worked out.

The Publications Committee has been continuing its work of putting order into the publishing field and is the subject of a separate report in this issue. The Chairman announced that the number of subscriptions to Europhysics Conference Abstracts was near the break-even point but far from saturation. The influence of individual members of EPS in encouraging their institutions to subscribe to the EPS publications - Europhysics News included - could do much to help keep these publications buoyant financially. It was incidentally, likely that the first series of the Conference Abstracts would contain eight rather than seven volumes of conferences as originally envisaged.

Authority was given to the Astronomy and Astrophysics Division to form a new Solar Physics Section which will be the subject of a separate article. The statutes of this new section will be examined in detail later by the Executive but this should not hamper recruitment or the beginning of work. Similarly the statutes of the Chemical Physics Section of the Atomic Physics Division were held over to allow further reflexion particularly on the exact form of the relationship with members of other bodies.

The question of new sections and their rules is not a matter that is treated lightly. The Condensed Matter Division has already six sections, the most recent being that on Surface and Interface Physics. There are however still subjects that do not seem to fit in, such as liquids and liquid crystals and it was not clear how best the physicists working in these areas could be served. The decision had been made nevertheless, not to form a section for dielectrics, ferro-electrics and related phenomena and these would be covered by the existing section of Semiconductors and Insulators.

The Chairman of the Nuclear Physics Division in addition to his survey of recent activities including the announcement of their first study conference (as defined by N. Kurti in EN, March, 1976) to take place in 1977, reported on the successful recruiting campaign carried out in FRG, Netherlands and U.K. which has resulted in the total membership of the Division rising to 430 and with a significant number of new members of EPS.

A main item on the Agenda of Council was the Fourth General Conference for which the Conference Committee has already put in a considerable amount of work. Council endorsed the main lines of the proposals that the Conference should consist of plenary sessions of broad appeal plus parallel sessions comprising symposia dealing with rather closely defined subjects. The philosophy was to concentrate on interdisciplinary topics and topics where there had been recent important steps forward. The difficulty, of course, is to know what will be the lead stories two years from now. The organization already provided for extensive consultation with and between the divisions. In each case a division will be responsible for the organization of a symposium in collaboration with other divisions with overlapping interests. EN will be regu- larly bringing news of the programme as it evolves and will content itself here by suggesting to readers that they reserve the week in 1978 starting September 25 for a journey to York, England.

A proposal emanating from the Atomic Physics Division which was taken up by the Council was for the organization of sponsored lectures whereby a lecture of outstanding significance could be presented by the speaker in, say, four different countries, preferably East and West. The executive was instructed to study how such a programme could be administered, the costs involved and so on.

Considerable enthusiasm was also voiced for the proposal that EPS should become more closely involved with scholarships for young physicists. Ideally the EPS should have a comprehensive library of information on the sources of funds and the qualifications required when scholarships were open to Europeans other than just national candidates. In addition the EPS should act as a central clearing house for such scholarships. There were evident difficulties in assembling the relevant information and in the EPS acting as the arbiter in the spending of other people's funds, but the Executive undertook to study the ideas put forward with a view to making specific proposals in due course. A lead was given by the immediate offer from the Ettore Majorana Centre at Erice of 10 scholarships/year put at the disposal of EPS.

A summary of the activities of this centre which runs 30 schools in a variety of subjects, sparked off a discussion on the need to analyse in as complete a way as possible the present position of summer schools. Council was reminded that the Executive had proposed several years ago an Advisory Committee to study the question and it was only for extraneous reasons this Committee had never come into being. It would probably be better now that a sub-committee of the Conference Committee be formed to take the matter up again.

The Society's publications in the future is a recurrent subject which is evidence of members' interest and the fact that conditions change. EPS does not have the capital to launch any major new enterprise at present and the national societies are, in general, finding the cost of publishing 
their own bulletins ever more burdensome. By eliminating the use of the local language, a common bulletin for all Europe would not in some respects be desirable but there are altruistic and economic forces at work which suggest that some form of combination might be worked out in the longer term.

No doubt a directory of institutions would be of very great value particularly if accompanied by a note on the nature of the research done there but its compilation was a huge job. One tentative along these lines might be to start with the compilation of a catalogue, listing where such information was obtainable and members were asked to inform the central secretariat of relevant documents published in their own region.

The question of improving information supplies and simplifying communication particularly between East and West cropped up on several occasions. The problem is generally one of mechanics rather than principle and a useful exchange of advice was accompanied by an exchange of appropriate addresses between chairmen of divisions and advisory committees and national delegates. The net result should be a speed-up in response all round.

Notable at this Council was the little time spent on administrative and financial matters - proof of the sound position the Society has now established and which should see it out of debt by the end of 1977. After just a few reminders that we mustn't be complacent, Council could move on to the election of the new Executive Committee, overwhelmingly accepting the recommendations of the outgoing executive. The composition of the new executive is as follows :

President: I. Ursu, Bucharest ; Vice-President :

W. Martienssen, Frankfurt/Main ; Secretary: M. Guenin, Geneva ;

Vice-Secretary: T. Riste, Kjeller ;

Treasurer: O. S. Heavens, York ;

Vice-Treasurer: J. J. Went, Arnhem ; Members :

H. B. G. Casimir, Eindhoven ;

S. Kapitza, Moscow ;

A. Lösche, Leipzig ;

P. Radvanyi, Orsay;

Z. Wilhelmi, Warsaw.

In thanking the Council for their expression of confidence in him, which he took also as a compliment to the physics practised in his own country, Professor Ursu spoke of the deep sense of responsibility he felt in following a predecessor whose professional competence and generous humanity seemed to predestine him permanently to preside over our Society. Prof. Casimir had enriched the
EPS to such an extent it had assumed a new meaning and he had proved for all time, in his own restrained and persuasive manner the practical reality of the EPS inspiration in Europe today.

The new president would, happily, be able to call on Prof. Casimir's wisdom over the coming year and he would be assisted by a remarkable team of people on the executive committee. It was nevertheless with great regret that the committee would now lose the services of J. Friedel, N. Cindro and K. Ganzhorn whose contributions to the EPS over these past five years had been so great. Their wide and sage experience would be missed.

The president saw his main goal in the future to be the promotion of European physics and the enhancement of the concept of physics as a major source of spiritual and material civilization. We must stress those elements in our midst that bind us together, we must encourage all forms of communication and cooperation between East and West so that ideas circulate freely and in all directions. We must pay attention to education and to raising standards and we should develop our relationships with national organizations and international organizations with interests similar to ours - notably the United Nations.

In reply, Professor Casimir spoke of the critical situation of four years ago in the EPS which required that the first priority should be to stabilize the Society in order to establish a sound basis upon which its activities could grow. That goal had been achieved and we had now a healthy organization, running well, which can look forward to growth and expansion in the future. He felt there was now a real community feeling amongst European physicists, a sense of belonging and a will to collaborate for the general benefit of physics and indeed mankind.

\section{Individual Ordinary Members}

The following have been accepted as Individual Ordinary Members of the EPS :

C. Cesarsky, Gif-sur-Yvette

M. Gassend, Winnipeg

D. May, London

J. Mydosh, Leiden

J. Mydosh, Leid

S.K. Sen, Winnipeg

D.N. Stacey, Oxford

J. Tai-Chai Chen, Hong Kong

P. Violino, Pisa

\section{Divisions}

The board of the Astronomy and Astrophysics Division has appointed K. Pinkau, Garching, as Chairman and C. Cesarsky, Saclay, as Secretary.

During the 8th Conference on Atomic Spectroscopy, which will take place in Oxford 13-16 July 1976, a General Assembly of the Atomic Spectroscopy Section of the Atomic Physics Division (EGAS) will be held. This assembly has to elect three new members to the board of EGAS. Resigning members are Dr. K. Bockasten (Lund), Prof. Dr. M. Dufay (Villeurbanne) and Prof. Dr. W.R.S. Garton, F.R.S., the last of whom is prepared to stand for re-election. The present board will nominate Prof. Dr. I. Martinson (Lund). Other nominations can be sent to the secretary of EGAS (c/o Dr. D.N. Stacey, Clarendon Laboratory, Oxford OX1 3PU, U.K.) before the beginning of the conference; they should be signed by three EGAS members and be accompanied by a statement of consent of the nominee.

The list of board members of the High Energy and Particle Physics Division published in the April issue should be amended as follows :

J. Hamilton, Copenhagen (not Brighton)

J. Laberrigue-Frolow, Paris (not Palaiseau)

\section{Member Societies}

The French Physical Society has elected Dr. C. de Dominicis from Saclay as President.

The Royal Irish Academy has elected Professor E.F. Fahy as chairman and Dr. E. Lalor as secretary, both of the Irish National Committee for Physics.

The Israel Physical Society has elected Prof. Charles G. Kuper as President and Prof. Raul Weil as secretary. Its new address is the Technion-Israel Institute of Technology, Technion City, Haifa.

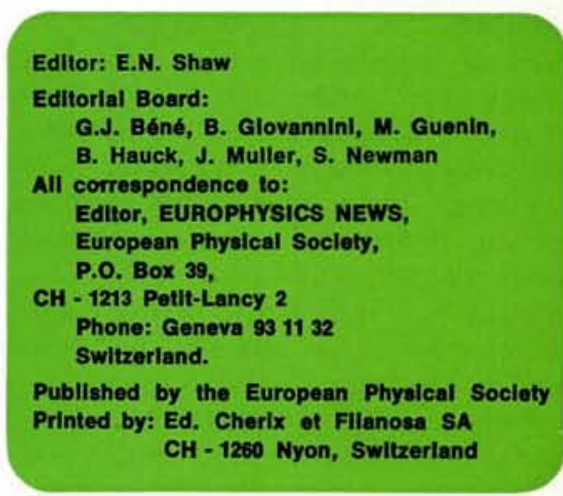

